\title{
Catalytic Effect of Transition Metals (Copper, Iron, and Nickel) on the Foaming and Properties of Sugar-Based Carbon Foams
}

\author{
Toni Varila ${ }^{1,2}$ (D) Henrik Romar $^{1} \cdot$ Ulla Lassi $^{1,2}$
}

Published online: 24 April 2019

(c) The Author(s) 2019

\begin{abstract}
Recently, bio-based carbon foams have gained much interest in many chemical industry fields because of their unique structure and properties. This study provides new information on the effects of catalytic metals (iron, nickel, and copper) on the foaming process. Specifically, the effects of these catalysts on the density, foam growth, and cell size and then further on the pore size distribution and specific surface areas after the physical activation are considered. Furthermore, some of the activated sugar foams were used in adsorption tests using methylene blue as adsorbent. Results showed that the highest effect on foam density was obtained using the iron catalyst in the foaming process. In addition, increasing the iron amount, the development of micro-pores decreased from 95.2 to $60.3 \%$ after cabonization and activation of the foams. Nickel and iron had the highest and lowest effect on foam rise at 1375 and 500\%, respectively. Interestingly, when the nickel catalyst was used, cell sizes and surface areas two times larger than those when the foams were prepared with the iron and copper catalysts was obtained. The specific surface area of activated sugar-based carbon foams changed significantly with the increased copper amount inside the foaming solution in compared with iron or nickel catalyst. Methylene blue adsorption capacity of additional series of activated sugar foams decreased from 28 to $9 \%$ when meso-pore amount decreased.
\end{abstract}

Keywords Sugar foams $\cdot$ Transition metals $\cdot$ Porosity $\cdot$ Physical activation $\cdot$ Foaming properties

\section{Introduction}

Activated carbons (ACs) are used for many applications in industrial and municipal processes, including wastewater treatment, gas cleaning processes, and metal removal from waste streams [1-3]. ACs have also been used as support for a heterogeneous catalyst or as a catalyst itself [4-6]. The consumption of AC is continuously increasing worldwide. Traditionally, ACs have been prepared from a number of carbon-rich materials, such as coconut shells, coal, and sawdust $[2,7,8]$.

Structured carbons or carbon foams are a type of carbons that have recently gained much interest. These carbon structures have been used in different applications, such as

Henrik Romar

henrik.romar@chydenius.fi

1 Research Unit of Sustainable Chemistry, University of Oulu, P.O. Box 3000, 90014 Oulu, Finland

2 University of Jyvaskyla, Kokkola University Consortium Chydenius, Applied Chemistry, P.O. Box 567, FI-67101 Kokkola, Finland adsorbents, catalyst supports, and even energy storage materials in batteries $[6,9,10]$. Sugar foams can be prepared using different raw materials, such as disaccharides, starch, and carboxylic acids (citric acid or oxalic acid), by direct polymerization using different metal catalysts. Another possible method for the preparation of carbon foams is to use chemical polymerization routes, such as the resorcinol-phenol route or a modification of this route by replacing the phenolic compound resorcinol with biomass containing significant amounts of phenolic compounds such as lignin or tannins $[11,12]$.

The main advantage of the preparation of carbon foams in comparison with the classical method for $\mathrm{AC}$ is that they can be prepared in high quantities under mild reaction conditions. Typically, temperatures below $200{ }^{\circ} \mathrm{C}$ and normal air pressure are used for the foaming process [9]. To convert carbon foams into ACs, a thermal treatment at high temperatures must be conducted.

Carbon foams generally have highly ordered structures, and high specific surface areas (SSAs) $\left(1000-3000 \mathrm{~m}^{2} / \mathrm{g}\right.$ ) can be achieved by the thermal treatment of the carbon foams combined with some activation agent. Under these 
conditions, well-defined pore size distributions can be achieved. The developed pores are mostly in the micro-pore or meso-pore regions. The conversion of the organic precursors into carbon foams is a catalytic reaction involving metals, such as nickel, zinc, or magnesium, as catalysts. Nitrate salts are used as precursors for the catalytic metals. As described in Reaction 1, the thermal breakdown of the nitrate and the gases formed during this process are a key part of the foaming process [13, 14].

The foaming reaction occurs at slightly elevated temperatures in the range of $120-160{ }^{\circ} \mathrm{C}$ because of the highly exothermic reactions making the initial stages self-feeding in terms of heat. Polymerization is a two-step process that starts with the evaporation of water used as a solvent. During this step, the glycosidic bonds between individual monosaccharide units (if disaccharides or starch is used) are broken, and units of free glucose and fructose are formed. After the evaporation step, the catalytic polymerization of the $\mathrm{OH}$ groups takes place, resulting in the formation of a structured carbon unit in which the $\mathrm{C}-\mathrm{O}-\mathrm{C}$ bonds connect the sugar units, which build up the backbone of the foam. Foaming of the carbon structure is mainly caused by the water released during the condensation reaction between two sugar molecules, but there are also other gas-releasing reactions taking place according to the general reaction described in Reaction 1 [13]. In this reaction, $M$ stands for metals used as catalysts, such as nickel, zinc, or magnesium.

$$
\begin{gathered}
\mathrm{C}_{12} \mathrm{H}_{12} \mathrm{O}_{11}+\mathrm{M}\left(\mathrm{NO}_{3}\right)_{2} * \mathrm{xH}_{2} \mathrm{O} \rightarrow \mathrm{C}_{\text {foam }}+\mathrm{MOH} \\
+\mathrm{N}_{2}(\mathrm{~g})+\mathrm{H}_{2} \mathrm{O}(\mathrm{g})+\mathrm{NO}_{\mathrm{x}}(\mathrm{g})+\mathrm{CO}_{2}(\mathrm{~g})
\end{gathered}
$$

(Reaction 1)

The formation of sucrose-based foams have previously been presented in the scientific literature [14-16] Prabhakaran et al. were the first ones to produce and study the properties regarding the foam rise, density, cell structure and mechanical strength of sugar based foams [16]. One disadvantage of using non-activated foams is their low mechanical stability, which can be increased by thermal treatment (carbonization) after the formation of foams. Thermal carbonization occurs at temperatures of $400-600{ }^{\circ} \mathrm{C}$ in an inert atmosphere, and can be followed by physical activation process into AC foams. The activation process is performed at temperatures of $700-900{ }^{\circ} \mathrm{C}$.

The work done here is a follow up work from previous publications [14-16]. The aim of this article is to investigate the impact of different metal-based catalysts used in different concentrations in the formulation of sugar foams on the physical properties such as specific surface area, pore development, cell sizes and densities on the activated sugar forms. In addition, a novel information about physical activation of sugar foams with steam and the use of these activated sugar foams in methylene blue adsorption is given. In the present study, a series of sucrose-based carbon foams was prepared using the catalytic metals nickel, iron, and copper to investigate the effects of the metal catalyst used and the catalyst amount given as wt $\%$ using 1,2, and $4 \mathrm{wt} \%$ of each metal, on the formation and properties of carbon foams. The foams produced were further carbonized and steam activated to produce $\mathrm{AC}$ foams with high specific surface areas (SSAs) and a high degree of micro-pores. The activated sugar foams produced in a different series using only nickel as catalysts were tested for their adsorptive properties in methylene blue removal in addition to the measurement of SSAs, pore volumes, and pore size distributions.

\section{Materials and Methods}

\subsection{Materials}

Analytical grade sucrose (99\%) and copper (II) nitrate hemi(pentahydrate) (98\%) provided by Alfa Aesar (Karlsruhe, Germany) and iron (III) nitrate nonahydrate and nickel (II) nitrate hexahydrate provided by Merck (Darmstadt, Germany) were used. All reagents were of pro-analysis purity and used without any further purification.

\subsection{Preparation of Sugar Foams}

A series of sugar foams was prepared with different transition metal catalysts using the nitrate salts as precursors $\left(\mathrm{Cu}\left(\mathrm{NO}_{3}\right)_{2} \times 9 \mathrm{H}_{2} \mathrm{O}, \mathrm{Ni}\left(\mathrm{NO}_{3}\right)_{2} \times 6 \mathrm{H}_{2} \mathrm{O}, \mathrm{Fe}\left(\mathrm{NO}_{3}\right)_{3} \times 9 \mathrm{H}_{2} \mathrm{O}\right)$ by the slight modification of the method described in [14]. Briefly, a number of solutions containing approximately $10 \mathrm{~g}$ of sucrose were dissolved in $10 \mathrm{ml}$ of distilled water in a $250 \mathrm{ml}$ long neck beaker. To each of the sugar solutions, different amounts of the metallic precursors were added to give the initial metal concentrations of $1 \mathrm{~m} \%, 2 \mathrm{~m} \%$, and $4 \mathrm{~m} \%$ calculated on the sugar basis. The formulation of each sugar foam is presented in Table 1. After the addition of all reagents, the solutions were mixed on a magnetic stirrer at room temperature for $1 \mathrm{~h}$ to obtain a homogeneous mixture of the compounds. For the final foaming, each solution $(20 \mathrm{ml})$ was placed in a narrow-necked beaker and kept in an oven at $120{ }^{\circ} \mathrm{C}$ for $48 \mathrm{~h}$ using natural convection. The samples were labeled according to the metal used and their mass \%. For example, SFCu 2 corresponds to a sugar foam (SF) made with $\mathrm{Cu}\left(\mathrm{NO}_{3}\right)_{2} \times 9 \mathrm{H}_{2} \mathrm{O}$ with a $\mathrm{Cu}$ mass of $2 \%$.

For the adsorption tests, an extra series of sugar foams was prepared in the same way as that mentioned above using the nickel catalyst only. The formulation of these foams is listed in Table 2. These sugar foams were labeled using only the amount of nickel catalyst used to avoid confusion between the SFCu, SFNi, and SFFe samples. 
Table 1 Formulations used for the preparation of carbon foams

\begin{tabular}{lllll}
\hline Sample name & $\begin{array}{l}\text { Mass of pre- } \\
\text { cursor }(\mathrm{g})\end{array}$ & $\begin{array}{l}\text { Metal } \\
(\text { mass } \%)\end{array}$ & $\begin{array}{l}\text { Mass of } \\
\text { sugar }(\mathrm{g})\end{array}$ & $\begin{array}{l}\text { Volume } \\
\text { water } \\
(\mathrm{ml})\end{array}$ \\
\hline SFNi 1.0 & 0.495 & 1 & 10 & 10 \\
SFNi 2.0 & 0.991 & 2 & 10 & 10 \\
SFNi 4.0 & 1.982 & 4 & 10 & 10 \\
SFCu 1.0 & 0.366 & 1 & 10 & 10 \\
SFCu 2.0 & 0.732 & 2 & 10 & 10 \\
SFCu 4.0 & 1.464 & 4 & 10 & 10 \\
SFFe 1.0 & 0.724 & 1 & 10 & 10 \\
SFFe 2.0 & 1.447 & 2 & 10 & 10 \\
SFFe 4.0 & 2.894 & 4 & 10 & 10 \\
\hline
\end{tabular}

Table 2 Summary of the solutions used for the preparation of sugarbased carbon foams

\begin{tabular}{llll}
\hline Sample name & $\begin{array}{l}\text { Nickel } \\
(\text { mass \%) }\end{array}$ & Mass of sugar & Volume water \\
\hline SF 0.1 & 0.1 & 10 & 10 \\
SF 1.0 & 1.0 & 10 & 10 \\
SF 2.0 & 2.0 & 10 & 10 \\
SF 4.0 & 4.0 & 10 & 10 \\
\hline
\end{tabular}

\subsection{Calculation of Foam Rise and Densities}

The changes in foam volume as a result of the polymerization reaction were regarded as foam rise and calculated on the basis of the changes in height. Foam rise was measured with different amounts of nickel, iron, and copper catalysts and a constant mass of sucrose. Foam rise was calculated as the height of the individual foams after $24 \mathrm{~h}$ of polymerization divided by the height of the individual starting material. The results were given as the percentage of the initial volumes.

The densities of each foam were characterized immediately after maturation at $120^{\circ} \mathrm{C}$ for $48 \mathrm{~h}$ by cutting pieces of known dimensions from the foams. The densities $(\rho)$ were obtained from Eq. 1 using the total weight and volume of each sample:

$\rho=\frac{m}{V}$

where $m$ is the weight of the sample, and $V$ is the total volume obtained by measuring the dimensions, length, height, and width of each rectangular sugar foam.

\subsection{Cell Sizes and Their Surface Areas}

Open cells or closed cells, which are limited by the bridges formed between the individual sugar molecules typical of the foams, are formed during the polymerization and foaming processes. In open cells, pores are connected to each other and form a porous interconnected network when air or water vapor passes through the material fast enough [17]. In the closed cell system, the pores are closed because of the trapped gases, thus forming a much denser material than those in the open cell system. These cells can be observed under a light microscope at low magnifications.

After maturation, the sugar foams were cut into thin plates $(0.2-0.3 \mathrm{~mm})$ using a palette knife. The plates were carefully placed under a stereomicroscope (Euromex, Holland) with a digital camera attached. Pictures of the foam structures were taken using a 20 -fold magnification. The pictures were processed with a computer software to calculate the mean values of the cell diameters and their relative surface areas. A total of 18 pictures, two per sample, were taken. From each picture, 10 random cells were selected and analyzed to minimize the statistical error in the results.

\subsection{Carbonization, Activation and Burn Off of the Sugar Foams}

Prior to the carbonization and activation procedure, the sugar foams were crushed using a mortar and pestle, and each foam was refluxed at $373 \mathrm{~K}$ for $1 \mathrm{~h}$ with $1 \mathrm{M}$ hydrochloric acid to remove the metals from the sugar foams. According to our (so far unpublished) results, the removal of metals before the thermal treatment step is essential to achieve significant yields in the thermal step. If metals are present at high temperatures (1073 $\mathrm{K}$ and above), the samples are destroyed completely with a burn-off close to $100 \%$.

After the pretreatment of the sugar foams, the foams were carbonized and steam activated in a one-step process in a stainless steel fixed-bed reactor placed in a tubular oven. During the carbonization and activation process, the reactor was flushed with inert gas (nitrogen) to avoid the oxidation of the samples. The nitrogen flush was continued during the whole process. The temperature was elevated from room temperature to $1073 \mathrm{~K}$ using a $10 \mathrm{~K} / \mathrm{min}$ ramp for nickel, iron, and copper catalyzed foams. Finally, the foams were steam activated at $1073 \mathrm{~K}$ for $2 \mathrm{~h}$ using a water feed of $30 \mathrm{~cm}^{3} /$ hour. For the foams used in MB-adsorption, physical activation was carried out at $1073 \mathrm{~K}$ using $7 \mathrm{~K} /$ min temperature ramp. At the target temperature, water flow of $30 \mathrm{~cm}^{3} /$ hour was turned on and held for $1 \mathrm{~h}$. Burn off (BO) value off each foams were calculated using Eq. 2 as follows,

$B O=\left(1-\frac{m(\text { after steam activation })}{m(\text { before steam activation })}\right) \times 100$

where $m$ is the mass of the sugar foam. 


\subsection{SSA and Pore Size Distribution}

The steam AC foams were analyzed for the SSAs, pore volumes, and pore size distributions. Prior to the measurements, portions of each sample (about $200 \mathrm{mg}$ ) were pretreated for $3 \mathrm{~h}$ at a low pressure $(2 \mu \mathrm{mHg})$ and an elevated temperature (413 K) to clean their surfaces. Adsorption isotherms were obtained by immersing the sample tubes in liquid nitrogen (76 K) to obtain isothermal conditions. Nitrogen was added to the samples in small steps, and the resulting isotherms were obtained. SSAs were calculated from the adsorption isotherms according to the Brunauer-Emmett-Teller (BET) method [18]. Pore size distributions were calculated using the density functional theory (DFT) algorithm [19] assuming slit-formed pores [20]. Using the setup of the Micromeritics ASAP 2020 (Micromeritics Instrument, Norcross, GA, USA), pores down to $1.5 \mathrm{~nm}$ in diameter were measured.

\subsection{Adsorptive Properties}

The activated sugar foams were tested for their adsorptive properties using the adsorption of methylene blue (MB) into the pores by the method described in Raposo et al. [21]. A solution containing $300 \mathrm{mg}$ of $\mathrm{MB}$ per liter $\mathrm{H}_{2} \mathrm{O}$ was prepared. About $100 \mathrm{ml}$ of this solution was transferred into Erlenmeyer flasks $250 \mathrm{ml}$ in volume, $100 \mathrm{mg}$ of the AC foam was added, and the solutions were continuously agitated for $24 \mathrm{~h}$ to achieve equilibrium between the adsorption and desorption of the test dye. The portions of each solution were filtered and diluted if needed, and the absorbance of the solution was measured at $664 \mathrm{~nm}$ on a Shimadzu UV-1800 double-beam spectrophotometer (North America analytical and measuring instruments, Columbia, USA). The concentration of the solution was calculated from a calibration line obtained with known concentrations of MB. The adsorped mass was calculated using Eq. 3, and the percentage of MB removed was calculated using Eq. 4.

$q(a b s)=\left(C_{0}-C_{t}\right) \times V / m$

\%removed $=\left(C_{0}-C_{t}\right) / C_{0}$

where $C_{0}$ is the initial concentration of MB $(300 \mathrm{mg} / \mathrm{l}), \mathrm{C}_{\mathrm{t}}$ is the measured concentration after $24 \mathrm{~h}, V$ is the volume of MB solution used, and $\mathrm{m}$ is the mass of the AC foam used.

\section{Results and Discussion}

\subsection{Effect of Catalyst Amounts on the Volume Increase and Density of the Sugar Foams}

The formation of sugar-based carbon foams was a result of the catalytic polymerization of the $\mathrm{OH}$ groups on the individual monosaccharide units, and this polymerization led to a split-off of the water molecules. The evaporation of the water molecules formed mainly caused the foaming of the sugars. According to the results of this study, the increase in the foams was highly dependent on the mass of the catalyst added. As presented in Fig. 1, a strong dependency exists between the catalyst added and the foaming properties of the samples. Despite the metal used, an increase in volume was obtained in all cases. Illustrative photograph of the effect of nickel catalyst amount on the foam volume rise is presented in Fig. 2. The highest volume changes were achieved using $4 \mathrm{~m} \%$ nickel or copper in the foaming process (1375 and 1163\%) and the lowest using iron as the catalyst (500\%).

The densities of the sugar foams behaved in contrast to the volume increase as presented in Fig. 1. As expected, when increasing the catalyst amount in the individual sugar foams, an almost linear decreasing effect was observed in the foams independent of the catalytic metal used. Different from the volume increase, a foam prepared with a $4 \mathrm{~m} \%$ of nickel catalyst inside obtained the lowest density of $0.021 \mathrm{~g} /$ $\mathrm{cm}^{3}$, whereas the foams prepared with iron or copper had the higher densities of 0.065 or $0.048 \mathrm{~g} / \mathrm{cm}^{3}$, respectively. The reason for this result is simple: the higher the volume increase is (as in the case of nickel and copper foams), the more hollower structure is formed inside the sugar foam. If the volume increase is low (as in the case of iron), the structure formed becomes more compact because of the absence of reaction gases, and thus denser materials are obtained. The same effect was observed by [22] in their study on the properties of polyurethane foams.

\subsection{Effect of the Catalyst Amount on the Cell Sizes and Surface Areas of the Cells}

Taken with a stereomicroscope, the pictures of the foams prepared with iron, copper, and nickel catalysts are presented in Fig. 3. As shown in the pictures, a highly porous open cell structure was formed during the foaming process independent of the catalyst used. The morphology of the open cells, according to the Fig. 3, were not perfectly shaped spheres moreover they looked more like ovals.

Based on the analysis of the cell sizes and surface areas of the sugar foams, an increase in catalyst amount inside the foaming solution had a negative effect on the cell sizes and surface areas in all cases. As an example, SFNi 1.0 had the mean cell size of $0.98 \mathrm{~mm}$ while SFNi 4.0 had mean cell size of $0.50 \mathrm{~mm}$ respectively. Furthermore, when using copper and iron as a catalyst in the foaming process, cell sizes almost two times smaller in diameter were obtained at low concentrations compared to the foams prepared with nickel catalyst. Mean value of cell diameter in case of iron was $0.50 \mathrm{~mm}$ and with copper 0.48 when $1 \mathrm{~m} \%$ of catalyst was 
Fig. 1 Effect of the catalyst amount on the volume increase (a) and density (b) of the sugar foams
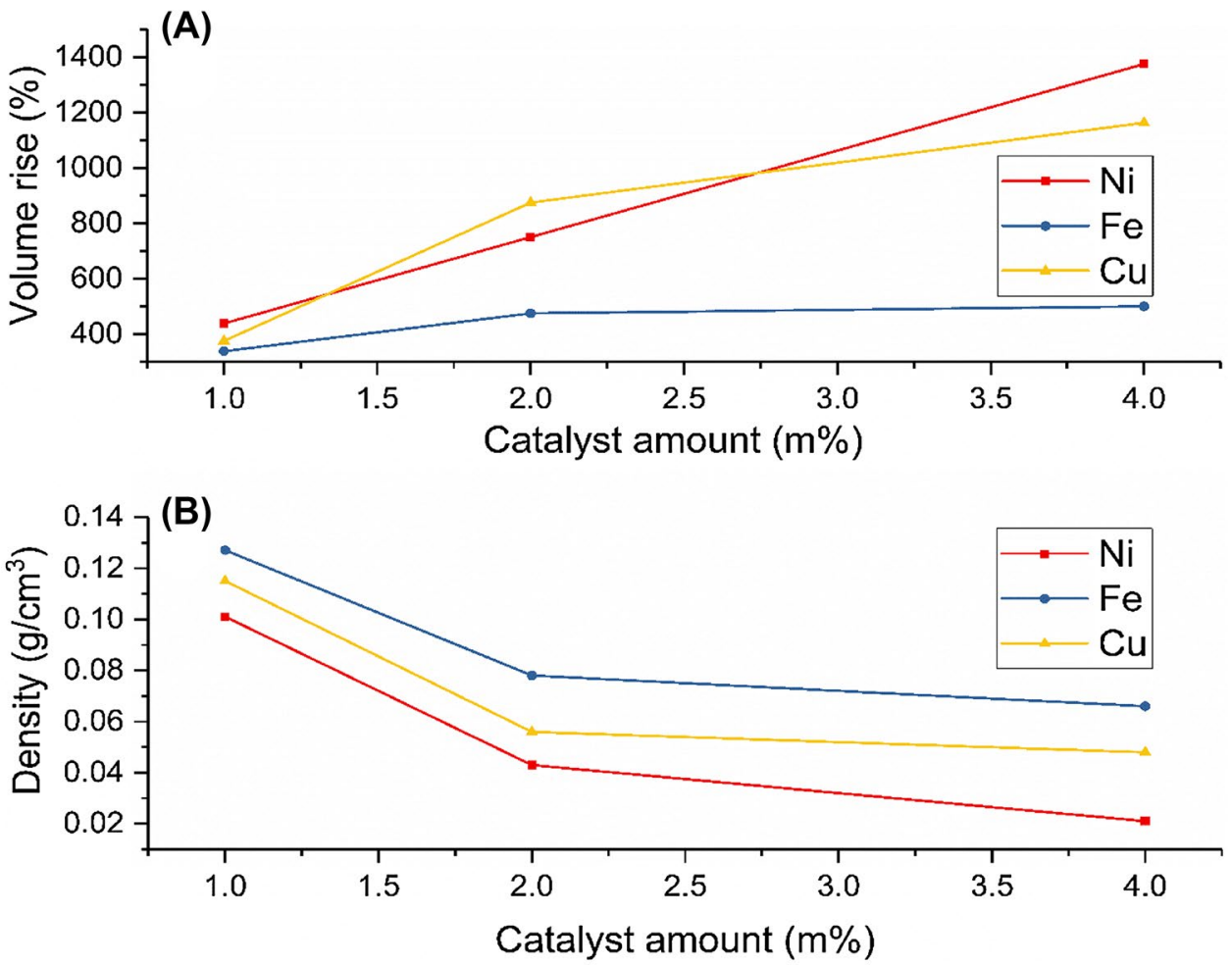

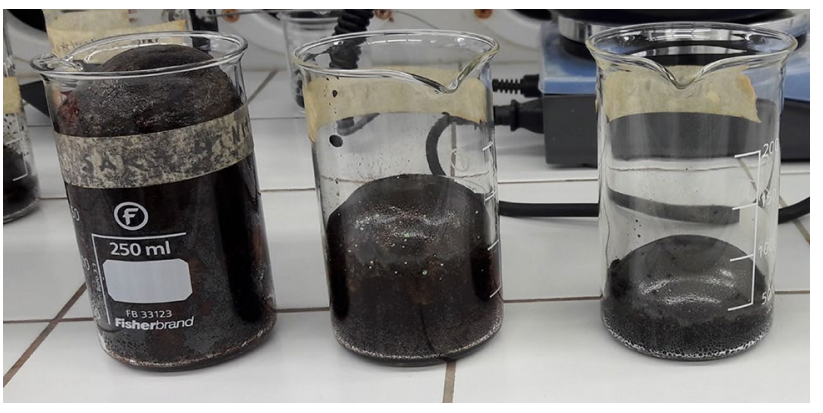

Fig. 2 Photograph of foams prepared with different nickel amounts. Highest $4 \mathrm{~m} \%$ of nickel on the left, middle $2 \mathrm{~m} \%$ of nickel and on the right $1 \mathrm{~m} \%$ of nickel

used in the formulation. Similar trend was noticed also in the surface areas of the cells. For the sample SFNi 1.0 mean cell surface area was $0.59 \mathrm{~mm}^{2}$ and for SFNi $4.00 .49 \mathrm{~mm}^{2}$ respectively. Comparing the corresponding values of samples SFCu 1.0, SFCu 4.0, SFFe 1.0 and SFFe 4.0 which were $0.32 \mathrm{~mm}^{2}, 0.25 \mathrm{~mm}^{2}, 0.30 \mathrm{~mm}^{2}$ and $0.28 \mathrm{~mm}^{2}$ with SFNi 1.0 and SFNi 4.0 samples, it seems that cell surface areas of nickel foams reduces at much higher rate than foams prepared with copper and nickel. In addition, same trend was observed while investigating the standard deviation of the cell sizes. Increasing the catalyst amount seem to have negative effect on the cell size variation as well. For sample SFNi 1.0 cell sizes variated from $0.45-1.45 \mathrm{~mm}$ and for SFNi 4.0 the $0.32-0.94 \mathrm{~mm}$, while deviation for $\mathrm{SFCu} 1.0$ and $\mathrm{SFCu}$ 4.0 samples were $0.28-0.90 \mathrm{~mm}$ and $0.14-0.67 \mathrm{~mm}$. For the samples SFFe 1.0 and SFFe 4.0 standard deviation were $0.36-0.65 \mathrm{~mm}$ and $0.17-0.66 \mathrm{~mm}$. According to the data shown, it can be said that properties of nickel foams are most affected by the catalyst amount. Reason for this interesting finding is detailed elsewhere [23, 24]. These findings are presented in Fig. 4.

\subsection{Porosity Analysis of Sugar-Based AC Foams}

The effects of the different catalysts used on the SSAs and pore size distribution of the ACs are difficult to directly link to the catalysts. However, the effects can be related to the structures created in the foaming process. The effects of the different catalyst used and their amounts on the adsorptive properties, such as the SSA pore volumes and pore size distributions, are presented in Fig. 4 and Table 3. The adsorption isotherms presented in Fig. 5 appears to be of Type I, which indicates the presence of microporous structures. One exception can be found in Fig. 5b, where a Type II isotherm can be observed as a result of an increased iron content, which indicates the development of more mesoporous carbon structures.

According to the results of the porosity analysis (Table 3), no clear trend in SSA and in the case of the foams prepared with $\mathrm{Ni}$ and $\mathrm{Fe}$ was found when the catalyst concentration was increased. Increased SSA from 560 to $868 \mathrm{~m}^{2} / \mathrm{g}$ and increased pore volume from 0.230 to $0.350 \mathrm{~cm}^{3} / \mathrm{g}$ was 


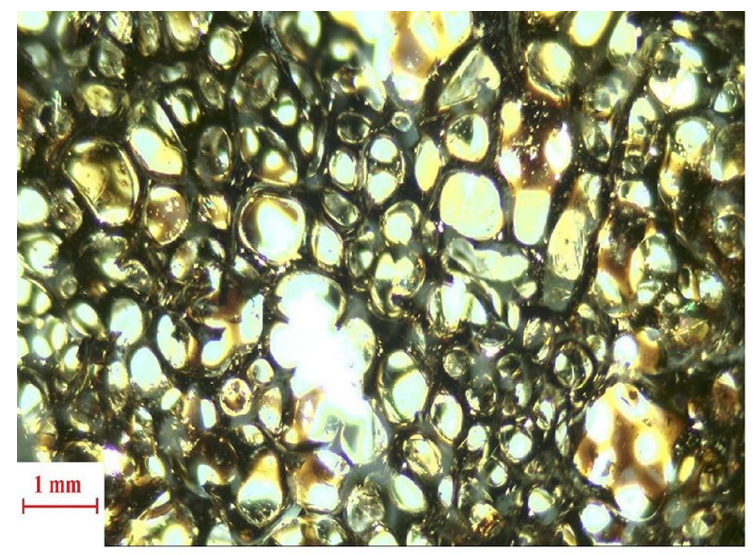

$\mathrm{Cu} 2 \%$

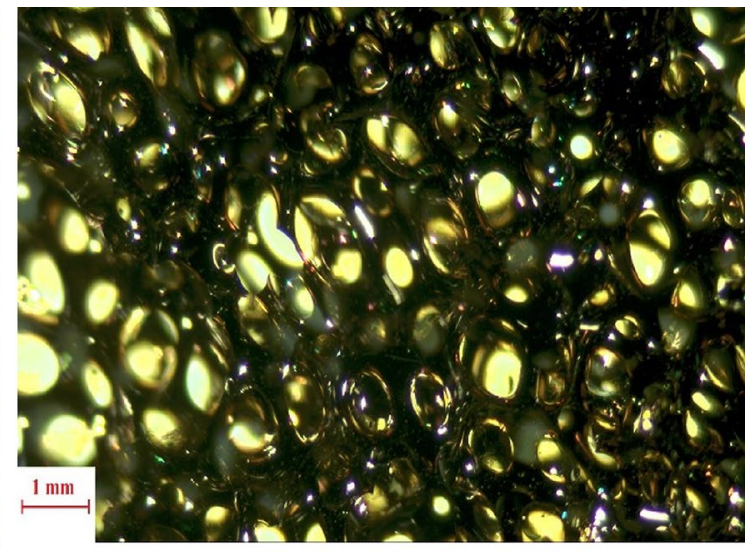

Ni $2 \%$

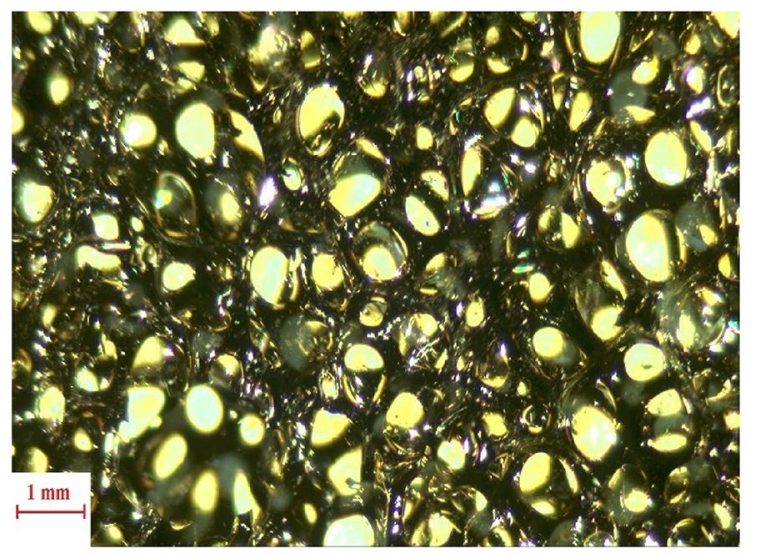

Fe $2 \%$

Fig. 3 Pictures of the open cell structures of the foams prepared with the different catalysts. Scale is the same in all three pictures

observed as a result of an increased catalyst concentration in the SFCu samples. Conversely, the pore volume in the case of the SFNi samples slightly decreased from 0.438 to $0.308 \mathrm{~cm}^{3} / \mathrm{g}$ with the increasing nickel amount.

As observed from the adsorption isotherms, the pores created during the activation were mostly micro-pores independent of catalyst amount used. This observation is even more evident in both the t-plot and DFT calculations. The micropore area according to the t-plot measurements was close to the SSA of the AC foams calculated by the BET model in all cases except SFFe_4.0. Thus, the formed surface areas in the AC foams consisted mainly of micro-pores.

The DFT model predictions of the pore size distribution confirmed that the pores were mostly microporous and that the change in the catalyst concentration only had a minor effect on distribution in the case of the SFNi and SFCu samples. However, the pore size distribution in the SFFe samples had some variation when different catalyst amounts were used. Microporosity decreased from 95.2 to $60.3 \%$. In other words, mesoporosity increased from 4.8 to $39.2 \%$. The burn-off of the activated sugar foams after two hour steam activation was in range of $64.2-85.3 \%$ and there seem to be no correlation between the catalyst amount used.

In terms of the additional series of sugar-based carbon foams prepared for the adsorption test using nickel as the catalyst, a minor differences was noticed in comparison with the SFNi samples. The porosity analysis of SFNi samples are also presented in Table 4 in a separate column. As expected a difference in the SSAs and pore volumes between the nickel, iron, and copper catalyzed foams and the nickel foams was observed, and it was due to the use of different temperature ramp and different steam activation time in the carbonization and activation stages. Slight decrease in the burn-off values, from 68 to $48 \%$, after one hour were obtained when increasing the nickel amount in additional series. The different effects observed between $\mathrm{Ni}$ and $\mathrm{Cu} / \mathrm{Fe}$ is interesting but so far no reasonable explanation can be presented.

\subsection{Adsorptive Properties}

The prepared additional series of sugar-based carbon foams was tested for adsorptive properties using the MB test. The 
Fig. 4 Effect of catalyst amount on the cell sizes (a) and surface areas $(\mathbf{b})$
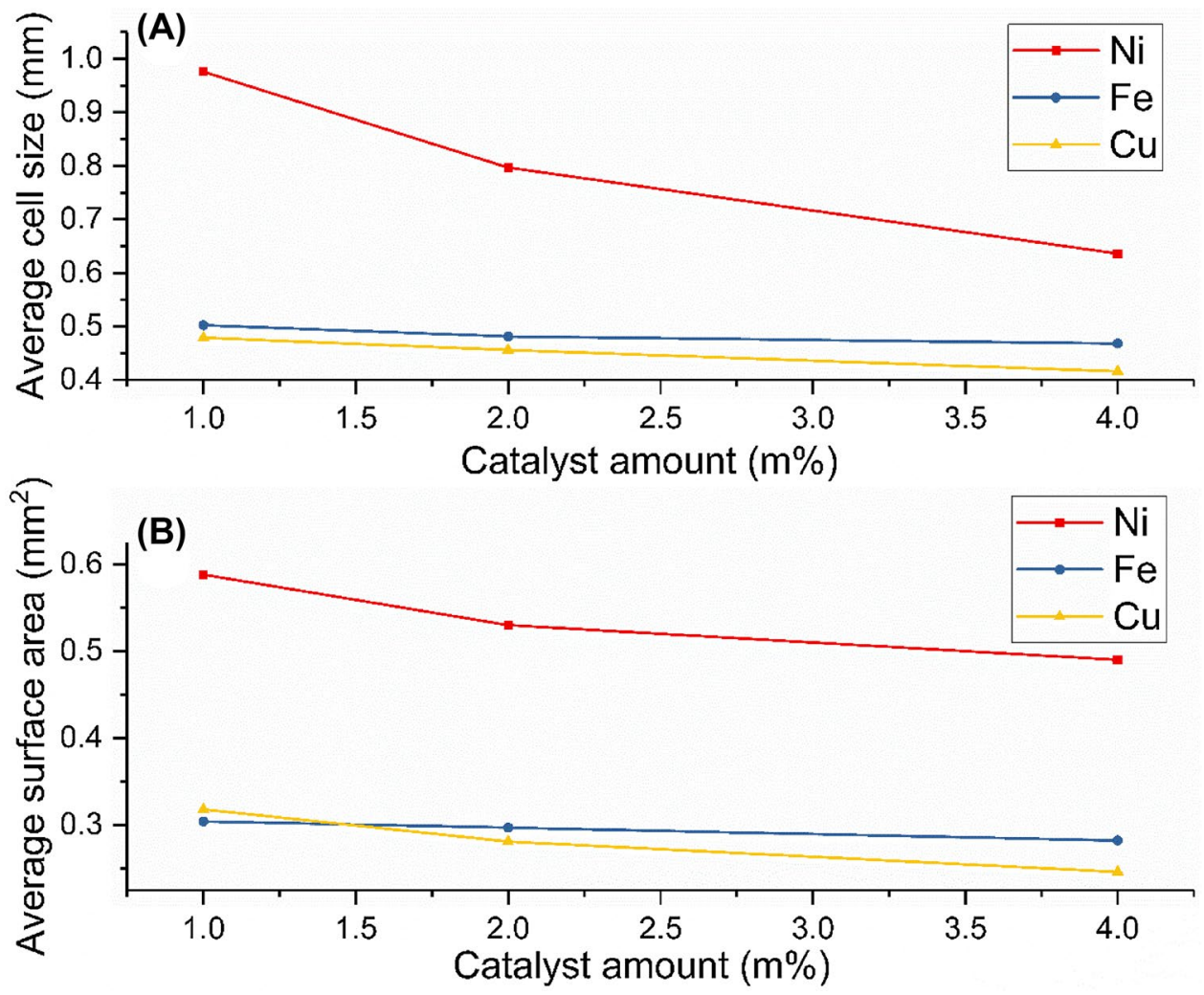

Table 3 Porosity analysis of the activated sugar-based carbon foams

\begin{tabular}{|c|c|c|c|c|c|c|c|c|c|c|c|c|c|c|}
\hline \multirow[b]{2}{*}{ Calculation method } & \multirow[b]{2}{*}{ Unit } & \multicolumn{3}{|l|}{$1 \mathrm{~m} \%$} & \multicolumn{3}{|l|}{$2 \mathrm{~m} \%$} & \multicolumn{3}{|l|}{$4 \mathrm{~m} \%$} & \multicolumn{4}{|c|}{ Additional series } \\
\hline & & SFNi & $\mathrm{SFCu}$ & SFFe & SFNi & $\mathrm{SFCu}$ & SFFe & SFNi & $\mathrm{SFCu}$ & SFFe & SF0.1 & SF1 & SF2 & SF4 \\
\hline \multicolumn{15}{|l|}{ BET } \\
\hline SSA & $\mathrm{m}^{2} \mathrm{~g}^{-1}$ & 817 & 560 & 770 & 735 & 770 & 630 & 758 & 868 & 745 & 601 & 489 & 570 & 304 \\
\hline Pore volume & $\mathrm{cm}^{3} \mathrm{~g}^{-1}$ & 0.438 & 0.230 & 0.330 & 0.428 & 0.316 & 0.299 & 0.308 & 0.348 & 0.450 & 0.380 & 0.258 & 0.290 & 0.138 \\
\hline Langmuir surface area & $\mathrm{m}^{2} \mathrm{~g}^{-1}$ & 936 & 635 & 861 & 805 & 846 & 691 & 828 & 932 & 825 & 685 & 557 & 636 & 346 \\
\hline \multicolumn{15}{|l|}{ t-plot } \\
\hline Micro-pore volume & $\mathrm{cm}^{3} \mathrm{~g}^{-1}$ & 0.297 & 0.206 & 0.276 & 0.253 & 0.272 & 0.217 & 0.270 & 0.304 & 0.232 & 0.204 & 0.177 & 0.199 & 0.110 \\
\hline Micro-pore area & $\mathrm{m}^{2} \mathrm{~g}^{-1}$ & 736 & 513 & 700 & 656 & 703 & 550 & 701 & 805 & 593 & 504 & 440 & 504 & 272 \\
\hline External surface area & $\mathrm{m}^{2} \mathrm{~g}^{-1}$ & 81 & 46 & 71 & 79 & 67 & 69 & 57 & 64 & 152 & 97 & 48 & 65 & 32 \\
\hline \multicolumn{15}{|l|}{ DFT } \\
\hline Total pore volume & $\mathrm{cm}^{3} \mathrm{~g}^{-1}$ & 0.365 & 0.192 & 0.270 & 0.348 & 0.261 & 0.237 & 0.255 & 0.288 & 0.380 & 0.251 & 0.207 & 0.219 & 0.110 \\
\hline Micro-pores & $\mathrm{cm}^{3} \mathrm{~g}^{-1}$ & 0.276 & 0.191 & 0.257 & 0.235 & 0.255 & 0.203 & 0.249 & 0.281 & 0.229 & 0.190 & 0.164 & 0.185 & 0.102 \\
\hline Meso-pores & $\mathrm{cm}^{3} \mathrm{~g}^{-1}$ & 0.070 & 0 & 0.013 & 0.091 & 0.003 & 0.031 & 0.003 & 0.004 & 0.149 & 0.048 & 0.028 & 0.022 & 0.006 \\
\hline Macro-pores & $\mathrm{cm}^{3} \mathrm{~g}^{-1}$ & 0.019 & 0.001 & 0 & 0.022 & 0.003 & 0.003 & 0.003 & 0.003 & 0.002 & 0.013 & 0.015 & 0.012 & 0.002 \\
\hline Micro-pores & $\%$ & 76 & 99.5 & 95.2 & 67.5 & 97.7 & 85.7 & 97.6 & 97.6 & 60.3 & 76 & 79 & 84 & 93 \\
\hline Meso-pores & $\%$ & 19 & 0 & 4.8 & 26.1 & 1.1 & 13.1 & 1.2 & 1.4 & 39.2 & 19 & 14 & 10 & 5 \\
\hline Macro-pores & $\%$ & 5 & 0.5 & 0 & 6.3 & 1.1 & 1.3 & 1.2 & 1 & 0.5 & 5 & 7 & 6 & 2 \\
\hline $\mathrm{BO}$ & $\%$ & 71.4 & 68.0 & 70.8 & 85.3 & 80.5 & 64.2 & 67.4 & 70.3 & 70.9 & 68.0 & 63.0 & 59.3 & 48.0 \\
\hline
\end{tabular}

$B E T$ Brunauer-Emmett-Teller method, DFT density functional theory, SSA specific surface area, $B O$ burn off after the activation 

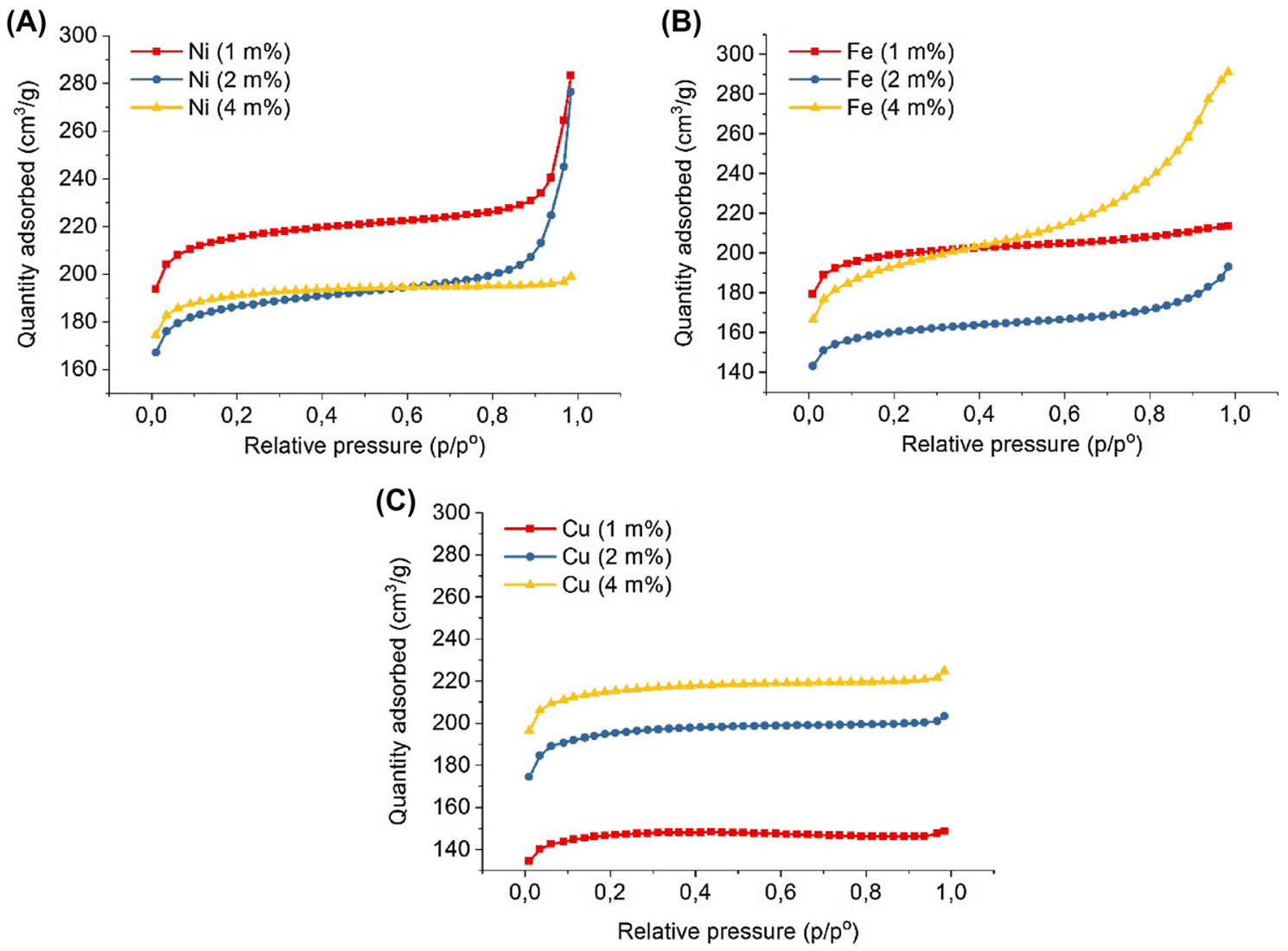

Fig. 5 Adsorption isotherms of the ACs prepared with different catalysts and catalyst amounts. a Ni catalyst, $\mathbf{b}$ Fe catalyst, and $\mathbf{c} \mathrm{Cu}$ catalyst

Table 4 Adsorption properties of the $\mathrm{AC}$ foams measured as the adsorption of $\mathrm{MB}$

\begin{tabular}{llll}
\hline Sample & Ni (mass \%) & $\begin{array}{l}\text { MB adsorbed } \\
(\%)\end{array}$ & $\begin{array}{l}\text { MB } \\
\text { adsorbed } \\
(\mathrm{mg} / \mathrm{g})\end{array}$ \\
\hline SF0.1 & 0.1 & 28 & 85.0 \\
SF1 & 1.0 & 23 & 69.6 \\
SF2 & 2.0 & 13 & 39.7 \\
SF4 & 4.0 & 9 & 28.5 \\
\hline
\end{tabular}

results of the tests (Table 4) indicate that the removal of the MB dye was lower than that normally obtained by ACs and that the adsorption maximum of the $\mathrm{AC}$ foams was $28 \%$ and $85 \mathrm{mg}_{\mathrm{MB}} / \mathrm{g}_{\mathrm{AC}}$.

The capacity to adsorp the MB seemed to correlate inversely with the mass of the catalyst used. When more nickel catalyst was added to the foaming solution, the material became less adsorptive and adsorption decreased from 28 to $9 \%$. Pore volume, mainly the pore size distribution, and the level of meso-pores appeared to correlate strongly with MB adsorption. Figure 6 shows that the higher the meso-pore amount inside the carbon is, the more $\mathrm{MB}$ is adsorped into the carbon. A higher catalyst content in the

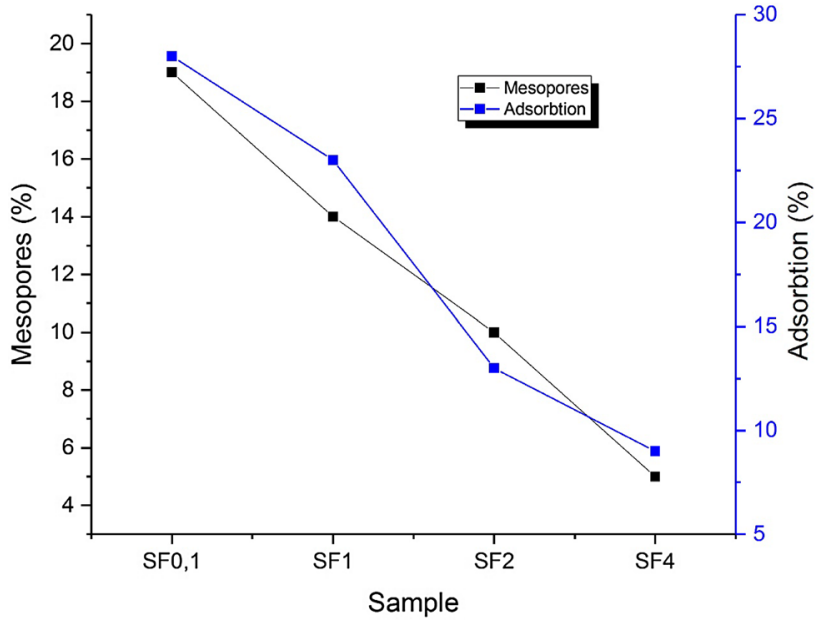

Fig. 6 Effect of meso-pores amount in sugar-based ACs on the MB adsorption capacity (\%)

sample seemed to decrease the adsorption ability. One possible reason for this interesting finding can be the size off methylene blue molecule. Micro-pores are too small for MB to be adsorped while meso-pores are much larger so MB can fit inside the pores. 


\section{Conclusion}

In this study, the effects of three different transition metal catalysts and their amounts on the properties of sugar-based carbon foams were investigated. According to the results, an evident correlation was found between the catalytic metals used and the properties of the foams formed, whether the foams were untreated, carbonized, or activated. The same correlation was also found between the concentrations of the individual metals and the properties of the foams. Apparently, affecting the properties of density, cell size, cell surface area, volume increase of the foam, pore size distribution, SSAs and MB adsorption was possible by increasing the catalyst amount and changing the catalyst in the foaming process. The result that was obtained created easy and flexible routes for the production of tailor-made ACs according to the demands of the final use of the ACs.

In sum, the greatest effect on the volume increase, cell size, and surface area was observed when nickel was used as a catalyst. Iron had the greatest effect on density and on the development of micro-pores of the sugar-based AC foams. Increasing the copper concentration in the initial foaming solution had the greatest effect on the SSA in comparison when the iron or nickel catalyst was used. A high nickel content in the sugar-based carbon foam samples increased the microporosity from 73 to $93 \%$, and the methylene blue adsorption capacity decreased from 28 to $9 \%$ because of the adsorptive ability of MB. This study shows that these materials are promising candidates for a number of applications, including catalytic support materials. Further investigation on the mechanical strength, mesoporosity, and testing in some syntheses is needed to produce more valuable products.

Acknowledgements Open access funding provided by University of Oulu including Oulu University Hospital. Toni Varila would like to thank the Green Bioraff Solutions Project (EU/Interreg/Botnia-Atlantica, 20201508) for funding this research.

Open Access This article is distributed under the terms of the Creative Commons Attribution 4.0 International License (http://creativeco mmons.org/licenses/by/4.0/), which permits unrestricted use, distribution, and reproduction in any medium, provided you give appropriate credit to the original author(s) and the source, provide a link to the Creative Commons license, and indicate if changes were made.

\section{References}

1. Fu T, Li Z (2015) Chem Eng Sci 135:3-20

2. Mohammad-Khah A, Ansari R (2009) Int J ChemTech Res 1:859

3. Ahmadpour A, Do DD (1996) Carbon 34:471-479

4. Klinke HB, Ahring BK, Schmidt AS, Thomsen AB (2002) Bioresour Technol 82:15-26

5. Yabushita M, Kobayashi H, Haraa K, Fukuoka A (2014) Catal Sci Technol 4:2312

6. Lam E, Luong JHT (2014) ACS Catal 4:3393-3410

7. Antal MJ, Gronli M (2003) Ind Eng Chem Res 42:1619

8. Ahmedna M, Marshall WE, Rao RM (2000) Bioresour Technol $71: 113-123$

9. Inagaki M, Qiu J, Guo Q (2015) Carbon 87:128-152

10. Li S, Pasc A, Fierro A, Celzard A (2016) J Mater Chem A 33:12686-12713

11. Zhang W, Ma Y, Wang C, Li S, Zhang M, Chu F (2013) Ind Crops Prod 43:326-333

12. Rosas JM, Berenguer R, JoséValero-Romero M, Rodríguez-Mirasol J, Cordero T (2014) Front Mater 1:1-17

13. Wang C, O'Connell MJ, Chan CK, Appl ACS (2015) Mater Interfaces 7:8952-8960

14. Jana P, Palomo del Barrio E, Fierro V, Medjahdi G, Celzard A (2016) Carbon 109:771-787

15. Narasimman R, Prabhakaran K (2012) Carbon 50:1999-2009

16. Prabhakaran K, Singh PK, Gokhale NM, Sharma SC (2007) J Mater Sci 42:3894-3900

17. Vijay D, Goetze P, Wulf R, Gross U (2018) Int J Heat Mass Transf 123:787-804

18. Brunauer S, Emmett PH, Teller E (1938) J Am Chem Soc 60:309-319

19. Seaton NA, Walton JPRB, Quirke N (1989) Carbon 27:853-861

20. Lastoskie C, Gubbins KE, Quirke N (1993) Langmuir 10: 2693

21. Raposo F, De La Rubia MA, Borja R (2009) J Hazard Mater 165:291-299

22. Abdel Hakim AA, Nassar M, Emam A, Sultan M (2011) Mater Chem Phys 129:301-307

23. Rosebrock G, Elgafy A, Beechem T, Lafdi K (2005) Carbon 43:3075-3087

24. Li S, Tian Y, Zhong Y, Yan X, Song Y, Guo Q, Shi J, Liu L (2011) Carbon 49:618-624

Publisher's Note Springer Nature remains neutral with regard to jurisdictional claims in published maps and institutional affiliations. 